\title{
EFFICIENCY MEASUREMENT OF CUSTOMER SERVICE CALL CENTER
}

\author{
Aleksandra Ducic \\ Faculty of organization science, University of Belgrade \\ ducicaleksandra@gmail.com \\ Gordana Savic \\ Faculty of organization science, University of Belgrade \\ gordana.savic@fon.bg.ac.rs \\ Milena Popovic \\ Faculty of organization science, University of Belgrade \\ milena.popovic@fon.bg.ac.rs
}

\begin{abstract}
Customer feedback has become an important policy instrument in the business company, and it is essential for the customer base and policy development. One of the evaluation methods of customer satisfaction and loyalty can be the reports that are created in the company's customer support center. Therefore, companies must maintain a high number of customers to be efficient and successful. Data Envelopment Analysis (DEA) is a linear programming based technique for measuring the relative efficiency of decision-making units (DMUs) where the presence of multiple inputs and outputs makes comparisons difficult. In this paper, the DEA method evaluates the efficiency rate of customer service in 29 call center companies. The study was conducted based on the obtained data for service performed through the telephone. DEA research is based on the data available for the period from September 2017 to April 2019. The main goal of this analysis is to determine which customer-suport call centers in the world are efficient and which are inefficient. Based on the results, it was established that a small number of centers are efficient in the observed period. Furthermore, for inefficient centers, comparing those to efficient ones, the DEA method is giving us information why they are inefficient and could direct the future development policy.
\end{abstract}

Keywords: Data envelopment analysis, Customer' service, Call center, Relative efficiency.

JEL classification: C67, C80

\section{INTRODUCTION}

In today's business environment, companies mainly rely on the income that comes from customers (Tsai \& Lu, 2009). Acquiring new and retaining customers is difficult and costly in term of marketing. Since the company tend to keep the current rather than to acquire the new customers, it needs to enable and promise that their customers will be satisfied and become loyal (Dučić, 2018). Besides the other components, customer satisfaction and loyalty also is related to the customer support system. Nowadays, customer support call centers become an integral part of the support system (Chicu et al., 2016). Therefore, the agents in call centers must perform their assignments effectively to contribute to the efficiency of the whole customer support centre (Dučić, 2018).

Customers contact centre to get support before, during and after a purchase. They get immediate access to support, resolutions for any issues, buying possibilities and information from friendly and knowledgeable employees. Contact centers let a customer get advice and information about the range, services and shopping, get help before, during and after buying. 
The customer's satisfaction is vital for one company. If we want our customers to be satisfied, then one contact centre has to be efficient. This means that employees have to provide customers with advice and answers, quick problem resolution and ensure the trust of the customer. Efficient customer support center needs efficient and knowledgeable employees if we want our customers to get advice from competent, skilled agents.

The efficiency of the agents and call centers may be evaluated using key performance indicators at the individual or companies level (Chicu et al., 2016). But, efficiency could be measured by creating an index as a combination of different input and output performance indicators. For that purpose, we suggest using Data Envelopment Analysis (DEA) method. DEA measures relative efficiency using various incommensurate inputs and outputs in the absence of market prices (Charnes et al., 1981). It provides a relative efficiency measure not relying on the application of a common weighting of the inputs and outputs (Tongzon, 2001). The field of DEA is growing steadily, bringing unabated interest from the management science and business communities, and continuing to be applied in practice to address new problems in policymaking and executives (Banker \& Podinovski, 2017). DEA is a suitable method for service evaluation and management (Sherman \& Zhu, 2006) since it provides parameters efficient projection and importance for each unit under evaluation. In this paper, we use DEA as a data-driven approach to give us information about customer support contact centers' efficiency and what is required to do in order to become efficient for each of them. The efficiency of 29 call centers, under one global, multinational company, in different countries all over the world, will be analyzed based on data in the period from September 2017 to April 2019. The results of the study showed that the call center could be effective only if it provides exceptional customer service; it means responding to challenging requests and solving within the shortest time possible.

The paper is composed as follows: Section 2 describes the DEA basics; Section 3 contains a study about the relative efficiency of customer service call centres, and finally, the main conclusions are summarized in the last section.

\section{METHODOLOGY - DATA ENVELOPMENT ANALYSIS (DEA)}

DEA is a nonparametric technique for measuring the efficiency of complex entities with various inputs and outputs (Charnes et al., 1978). Based on the data on inputs and outputs, such an analysis can determine whether the individual decision-making unit (DMU) is going to be decided as inefficient, enveloped by orefficient one placed on the efficiency frontier.

There are numerous modifications of DEA models depending on whether inputs or outputs are deemed controllable or part thereof, whether constant or variable returns to scale are allowed, and so on (Banker \& Podinovski, 2017). The basic output-oriented, a constant returns-to-scale (CRS) model (Charnes et al., 1978) is as follows:

$$
\begin{aligned}
& \min h_{k}=\sum_{r=1}^{s} u_{r} y_{r k} \\
& \text { s.t. } \\
& \sum_{i=1}^{m} v_{i} x_{i k}=1 \\
& \sum_{r=1}^{s} u_{r} y_{r j}-\sum_{i=1}^{m} v_{i} x_{i j} \geq 0, j=1,2, \ldots, n \\
& u_{r} \geq \varepsilon, r=1,2, \ldots, s \\
& v_{i} \geq \varepsilon, i=1,2, \ldots, m
\end{aligned}
$$

where:

- $x_{i k}$ is the level of input $i$ th of DMUkth;

- $y_{r k}$ is the level of input $r$ th of DMU $k$ th;

- $h_{k}$-relative efficiency of $\mathrm{DMU}_{k}$ (obtained as maximum possible achievement in comparison with the other DMUs under the evaluation);

- $u_{r}$ are weights assigned to the $r$ th outputs, $r=1, . ., s$; 
- $\quad v_{i}$-are weights assigned to the $i$ th inputs, $i=1, . ., m$;

- $\varepsilon$ small nonnegative number..

This basic CCR DEA model should be solved $n$ times, once for each $\mathrm{DMU}_{k}$. The efficiency score of the observed $\mathrm{DMU}_{k}$ is given as virtual outputs (sum of weighted outputs).

\section{EFFICIENCY MEASUREMENT OF CUSTOMER SERVICE CALL CENTER}

\subsection{Customer support contact centre}

Contact centers are widely used to allow an enterprise or business to efficiently handle customer enquiries, complaints and support, and to allow an enterprise to make contact with existing or potential customers.

Contact Center is one part of a company responsible for support to the customers' needs. It is a crucial element of being multi-channel since it connects all those channels (Aksinet al., 2007). They are widely used to provide support throughout the whole process of buying in trying to increase or maintain customer satisfaction. Customers contact call centers via different methods. Having more contact methods ensures a higher possibility of serving more customers. The traditional name for the contact center was call center because they had only one contact method, and that was the phone. Even nowadays, the main contact method still is the phone. But today almost all contact centers provide other supportive contact methods like mail, chat, and social media. This is the reason why the name call center evaluated into the Contact Center (Dučić, 2018).

In one contact center agents answer to all customer questions, and they are mainly responsible for customer satisfaction. Since the issues might be different, contact center is divided into groups or teams responsible for the particular set of of customer's needs. If one team is too busy, the customer will be transferred to another less busy queue. Aim of creating different teams is serving customers as fast as possible to improve customer satisfaction related to waiting time.

On, the other hand, comparing to the traditional contact centers, today virtual centers enables their employee to work from home. This is a comfortable way of working because in this way employee feels more relax and become more productive. Also, this way of working affects

lower costs for the company. Remote working presents a very popular form of working today. In some periods this should be very useful and essential for one company in pandemic periods too when only this way of working is possible. Therefore, Contact Centers are essential for companies because they present direct connections between one company and customers charge for handling customer enquiries, complaints and support and to provide existing or potential customers (Delaney, 2005). Through the Contact Center, companies know what they should change to improve their business and cover all customers' needs.

Efficiency evaluation can be done on the individual level of employees at the level of contact centers. In the rest of this section some we will discuss operating on each of those levels.

\subsection{Contact Centers' Efficiency Measurement}

Customer support efficiency depends on employees' efficiency. One way of evaluating their efficiency is through communication with customers in order to estimate if company values are respected or not. The customer support centre's Team Leader chooses randomly one conversation for one employee and evaluates if he/she presented the company in the best possible way and respected all company's values. The highest score that one employee can get is $100 \%$. The form of evaluating is the same for all contacts methods. But this is only one way. Different tools for customer support resource evaluation have been developed. For 
example, Anderson and Ramsey (2007) developed a system for peer group evaluation to compare expected and actual behaviour in real-time.

The determinants of one contact centre are divided into three groups of indicators: employee attitude, employee performance and company system's performance (Chicuet al., 2016). Data on those indicators can be collected through a survey or captured from applications used by employees and later efficiency measurement. As an example, the customer service representative's performance is evaluating using DEA/network model (Poykayil Jayananda Panicker, 2002). Fuzzy Sets are used in paper to overcome the issue of data imprecision. Obviously, DEA method is proven to be an appropriate method of individual efficiency evaluation (Zbranek, P. 2013; Khodamoradi et al., 2016). The DEA can be used even when the service quality needs to be measured for example in education (Popović et al., 2020) or in sports industry (Ruiz et al., 2013; Radovanović et al., 2014). DEA is also used for measuring contact centres efficiency based on similar determinants (So, 2007; Mohammadi et al., 2017).

\subsection{Contact Center Technology}

In this paper, the efficiency of the contact centers of one global manufacture company will be evaluated. . In the scope of this company are home products and services related to assembly and delivery. In this contact centre, one employee is familiar with 20 applications, simultaneously using more than two from time to time. One of the essential technologies for all customer support centres is IVR (Interactive Voice Response). All incoming contacts have to go thought IVR and possibly reach the responsible agent. Depending on questions, customers will be placed in queue specific for resolving those kinds of problems. Other applications needed for regular daily routine are a system for receiving calls, application for claims and sales, application for tagging the calls or chatting application (Dučić, 2018).

The system for receiving calls offers a complete scope of programs and services to the contact centre. For example, the application for claims and sales is a system for processing and handling requests. This system helps to take care of customers' demands from registration to problem solution. Through this system, the company can have a whole history of all claims and information about our customers' issues. Application for tagging calls is an application for tagging and recording why customers are calling the contact centre. The company uses those applications to collect the big data on services, products and the reasons for customer dissatisfaction. Having this big database, data-driven approaches can be used for determining and predict the most demanding services and products and most frequents customer complaints (Moazeni \& Andrade, 2018). Chat applications allow reviving and answering on web pages during customer visitation.

\subsection{Efficiency Indicators}

Key performance indicators (KPI) help to clarify the most critical areas to drive customer experience, as well as the mission of the contact centre. To monitor performance, the contact centre has to define and measure KPIs. Based on KPIs, it is possible to evaluate performance and to make plans for improvements. The contact centre has to recognise performance which is instrumental in improving customer satisfaction and loyalty. All KPI are essential measures that give a good sign if the business is performing in line with overall business goals. KPIs are different for each of the contact methods.

In this paper, contact centers' efficiency will be evaluated only for one contact method / the call. All important KPIs are listed below covering all three determinants of service quality (Chicu et al., 2016):

1. Phone Service Level - number of responses to customer calls within the service level. This KPI is measured as the ratio of the number of answered calls within 60 
seconds to the total number of the incoming call. This KPI has to be continuously monitored in the real-time.

2. Call Volume Offered to IVR - the total volume of incoming calls to IVR system in a particular period.

3. Call Volume Offered to Queue - the ratio of the total number of calls in a particular period to the number of calls queuing for the agent. This KPI is commonly followed on a monthly level.

4. Call Volume Answered by Co-Workers - the total volume of inbound customer calls handled or answered by agents. This KPI should be monitored continuously and in real-time.

5. Average Speed of Answer - the average waiting time. The cancelled calls should be taking into calculation carefully.

6. Average Handle Time - the average time agents spend processing a transaction, including time spent in communication with end-users.

7. Average Hold Time - the average time customers were on hold.

8. Average After Call Work - the average unavailable time of agents necessary to finish additional activities after finishing the previous call.

9. Call Volume Abandoned in Queue-the number of calls that are disconnected by the caller or incorrectly answered.

10. Inbound Noncustomer calls- the number of calls coming from other sources than customers.

11. Outbound Calls - the number of calls directed from agents to customers. The purpose of this call is mostly informing customers about claims, the status of their order, or other reasons.

12. Self-served indicator - the share of calls completed using IVR Self-Serve Functionality out of the total offered calls to the IVR.

13. IVR Abandonment Rate - the percentage of callers who contact the IVR, perform no meaningful task and abandon.

14. Transferred Calls Volume - the total number of calls that are transferred from one queue to another queue.

15. Hours of Serviceare not part of the KPIs but also crucial since the number of hours depends on the number of served customers.

At the beginning of each month, Business Analysts in each of the call centers create standard monthly reports containing all those KPIs.

\subsection{Efficiency Results- Case study}

It is already mentioned that the main objective of this case study is to determine the relative efficiency index of 29 call centers in 29 countries all over the world operating inside the multinational company As we already mentioned, the contact centers' performance are monitored using the monthly reports containing multiple KPIs listed in the previous section. In order to ease performance monitoring, we are making one efficiency index using some of the essential KPIs as inputs and outputs and DEA model (1-5). The parameters (Malhotra \& Mukherjee, 2004; Carlaw et al., 2003) used for the solving CRS DEA model are as follows. Inputs:

1. Number of employees

2. Average handling time (hh:mm:ss)

3. Number of offered calls (monthly)

Outputs:

1. Number of answered calls (monthly) 
2. Number of calls answered within 60 seconds ("Service level")

Average handling time is one of the key measures for any contact center planning system because it tells how long a new item of work takes to be handled as well as the talk time. The number of calls answered depends on the services offered. If one call center has a higher number of offered calls, a higher number of employees follows it. If one call center has a higher number of employees, it probably would have higher performance and would achieve better results. Service level is a measurable number of services provided to a customer within a given period. In the context of this study, this parameter is used to measure the percentage of incoming calls that agents answer live during the 60 seconds. Descriptive statistics of those input and output parameters values overall observed period,, is given in Table 1.

Table 1. Descriptive Statistics

\begin{tabular}{|c|c|c|c|c|c|}
\hline Parameters & $\begin{array}{c}\text { Average } \\
\text { handling } \\
\text { time (in } \\
\text { minutes) }\end{array}$ & $\begin{array}{l}\text { Number of } \\
\text { offered calls }\end{array}$ & $\begin{array}{l}\text { Number of } \\
\text { employees }\end{array}$ & $\begin{array}{l}\text { "Service level" } \\
\text { calls (calls } \\
\text { answered in } 60 \\
\text { seconds) }\end{array}$ & $\begin{array}{l}\text { Number of } \\
\text { answered } \\
\text { calls }\end{array}$ \\
\hline Max & 16.307 & 5377321 & 12795.00 & 2048569 & 3833847 \\
\hline Min & 3.145 & 72510 & 414.00 & 59653 & 66614 \\
\hline Mean & 7.662 & 1189978 & 4425.81 & 511185 & 943756 \\
\hline Std. Dev. & 3.086 & 1165987 & 3494.03 & 493380 & 884201 \\
\hline \multicolumn{6}{|c|}{ Correlation coefficients } \\
\hline $\begin{array}{l}\text { Number of } \\
\text { employees }\end{array}$ & 1 & & & & \\
\hline $\begin{array}{c}\text { Average } \\
\text { handling time }\end{array}$ & 0.385 & 1 & & & \\
\hline $\begin{array}{l}\text { Number of } \\
\text { offered calls }\end{array}$ & 0.572 & 0.859 & 1 & & \\
\hline $\begin{array}{c}\text { Number of } \\
\text { answered calls }\end{array}$ & 0.157 & 0.798 & 0.920 & 1 & \\
\hline "Service level" & 0.343 & 0.981 & 0.827 & 0.889 & 1 \\
\hline
\end{tabular}

The first part of Table 1 shows the size of call centers varies in all parameters. Nevertheless, we decided to use CCR DEA model for efficiency evaluation since all call centers operate under the same company using the same policy. Therefore, we are expecting that increasing inputs should increase outputs in a similar proportion. The correlation analysis proved that there is an isotonicity between inputs and outputs.

The analysis covers the period from September 2017 to April 2019. Based on the input data, it can be noticed that the longest handle time of any call that the agent handled was in December 2017. It can be described by the fact that around the Christmas advertising period competition for customer's attention is high. The number of offered calls depends on the country where the call center is located. It can be noticed that the total number of calls is higher in the countries with a higher number of citizens. Germany and the USA have the largest number of offered as well as answered calls.

In September 2017, in Serbia the first store was opened, so the interest and the number of offered calls were very high compared to other months. Otherwise, the number of employees was the lowest in this month. Slovakia, Croatia, and Hungary are having the lowest number of employees compared with other countries.

According to the analysis of "Service level" calls, Romania has the best performance during the observed period with $99 \%$ of answered calls in 60 seconds followed by a call center in 
Slovakia which has $93 \%$ of this rate. The Nederland and Hungary had the lowest rate of "Service level" calls in November 2018 when they reached only $7 \%$ of answered calls.

The second part of Table 2 shows the correlation between overall inputs and outputs. The number of offered and answered calls has a very strong positive correlation of 0.92 and this result is close to 1 . This is logical because if one customer support center receives more calls with a higher number of employees than the number of answered calls will be higher. Service level and the number of answered calls with an average handling time have also a positive correlation but not strong. The reason is that if agents talks with customers too long then the possibility to answer to all customers is very low. For service level the logic is the same. If average handling time is higher this means that more customers are waiting in queue to be answered.

The EMS software (Efficiency measurement system) tool was used to solve the CRS DEA model, and the results obtained are shown in the Figure 1 and Table 2. More precisely, Figure 1 shows the number of relative efficient and inefficient call centers per each month during the observed period.

Figure 1: Number of efficient and inefficient countries per month

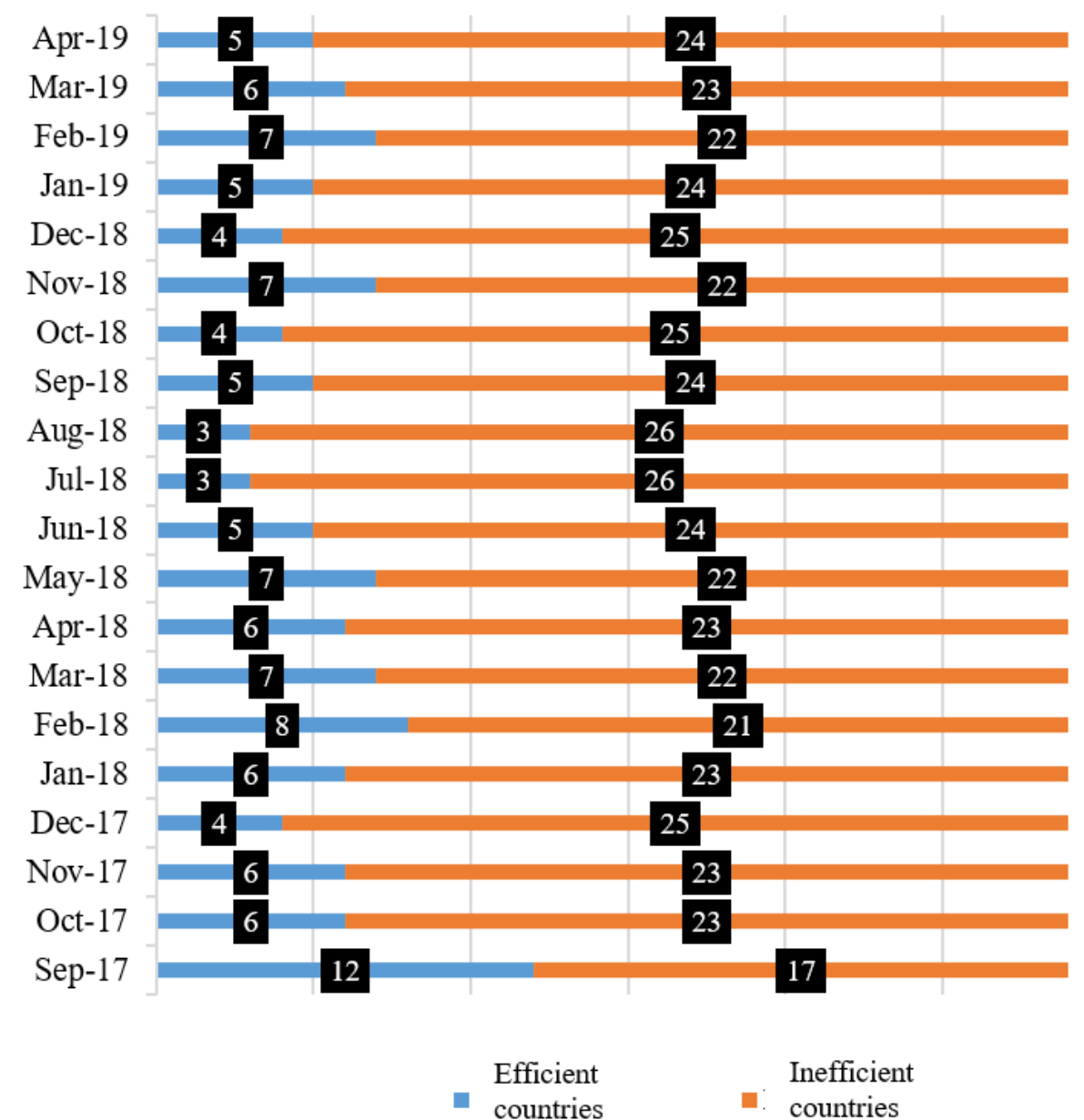

Based on the results, a few call centers are relatively efficient (Figure 1). The highest number of efficient call centers is in September 2017 while July 2018 and August 2018 are the months when it was the highest number of inefficient countries. It is assumed that one of the 
reasons lay in the fact that most employees go to vacation in the period August to September. No one call center except Slovakia was efficient in all months which is visible in Table 2.

Table 2: Results of the measuring call centers efficiency

\begin{tabular}{|c|c|c|c|c|c|c|c|c|c|c|c|c|c|c|c|c|c|c|c|c|c|c|}
\hline & \multicolumn{20}{|c|}{ Efficiency rate } & & \\
\hline & \multicolumn{4}{|c|}{2017} & \multicolumn{12}{|c|}{2018} & \multicolumn{4}{|c|}{2019} & & \\
\hline & Sep & Oct & Nov & Dec & Jan & Feb & Mar & Apr & May & Jun & Jul & Aug & Sep & Oct & Nov & Dec & Jan & Feb & Mar & Apr & Avg. & Rank \\
\hline Austria & 0.84 & 1 & 1 & 1 & 1 & 1 & 1 & 1 & 0.93 & 0.89 & 0.83 & 0.78 & 0.76 & 0.87 & 0.89 & 0.92 & 1 & 1 & 0.98 & 0.91 & 0.930 & 11 \\
\hline Australia & 0.95 & 0.89 & 0.86 & 0.69 & 0.88 & 0.91 & 0.75 & 0.88 & 0.75 & 0.62 & 0.56 & 0.77 & 0.77 & 0.7 & 0.66 & 0.57 & 0.69 & 0.73 & 0.83 & 0.84 & 0.765 & 22 \\
\hline Belgium & 0.47 & 0.58 & 0.49 & 0.39 & 0.49 & 0.78 & 0.72 & 0.75 & 0.75 & 0.84 & 0.79 & 0.84 & 0.83 & 0.73 & 0.45 & 0.59 & 0.74 & 0.75 & 0.78 & 0.83 & 0.680 & 24 \\
\hline Canada & 1 & 1 & 1 & 1 & 1 & 1 & 1 & 1 & 1 & 1 & 0.92 & 1 & 1 & 1 & 1 & 1 & 1 & 1 & 0.93 & 0.78 & 0.982 & 4 \\
\hline $\begin{array}{l}\text { Switzer- } \\
\text { land }\end{array}$ & .98 & 0.83 & 75 & 0.82 & 0.84 & 0.88 & 0.79 & 0.83 & 0.97 & 0.96 & 1 & 0.9 & 0.54 & 0.95 & 0.96 & 0.92 & 0.82 & 0.81 & 0.84 & 0.8 & .860 & 15 \\
\hline China & 1 & 1 & 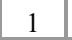 & 0.92 & 1 & 1 & 1 & 1 & 1 & 1 & 1 & 1 & 1 & 1 & 1 & 1 & 1 & 0.86 & 0.78 & 0.68 & .962 & 6 \\
\hline & 1 & 1 & 1 & 1 & 1 & 1 & 1 & 1 & 1 & 1 & 1 & 1 & 1 & 1 & 1 & 0.98 & 1 & 1 & 1 & 1 & 0.999 & 2 \\
\hline Germany & 0.37 & 0.29 & 0.27 & 0.22 & 0.36 & 0.4 & 0.46 & 0.55 & 0.57 & 0.44 & 0.36 & 0.49 & 0.48 & 0.44 & 0.38 & 0.26 & 0.43 & 0.41 & 0.29 & 0.31 & 0.389 & 29 \\
\hline Denmark & & 0.85 & 83 & 0.89 & 0.82 & 0.81 & 0.73 & 0.68 & 0.84 & 0.82 & 0.87 & 0.77 & 0.93 & 0.98 & 0.92 & 0.94 & 0.95 & 0.94 & 0.95 & 0.82 & .862 & 14 \\
\hline Spain & 0.97 & 0.91 & .77 & 0.71 & 0.69 & 0.79 & 0.82 & 0.85 & 0.78 & 0.54 & 0.57 & 0.79 & 1 & 1 & 1 & 1 & 0.98 & 0.97 & 0.88 & 0.69 & 0.836 & 17 \\
\hline Finland & 0.93 & 1 & 0.85 & 0.71 & 0.93 & 0.93 & 0.94 & 0.84 & 0.84 & 0.87 & 1 & 0.77 & 0.84 & 0.84 & 0.8 & 0.77 & 0.72 & 0.65 & 0.28 & 0.69 & 0.810 & 19 \\
\hline France & 0.52 & 0.59 & 0.62 & 0.66 & 0.62 & 0.69 & 0.65 & 0.64 & 0.65 & 0.65 & 0.71 & 0.68 & 0.66 & 0.66 & 0.69 & 0.67 & 0.63 & 0.63 & 0.56 & 0.49 & 0.634 & 26 \\
\hline Croatia & 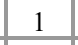 & 1 & & 0.96 & 0.98 & 0.98 & 1 & 1 & 1 & 0.76 & 0.93 & 1 & 1 & 0.94 & 1 & 0.97 & 0.85 & 0.81 & 0.85 & 0.67 & 0.935 & 10 \\
\hline Hungary & 0.87 & 0.65 & .69 & 0.62 & 0.72 & 0.79 & 0.8 & 0.82 & 0.82 & 0.91 & 0.85 & 0.73 & 0.77 & 1 & 0.69 & 0.53 & 1 & 0.91 & 0.87 & 0.81 & 0.793 & 21 \\
\hline Ireland & & 1 & 0.97 & 0.78 & 0.79 & & 1 & 0.98 & 1 & 1 & 1 & 0.83 & 0.81 & 1 & 1 & 1 & 1 & 1 & 1 & 1 & 0.956 & 7 \\
\hline Italia & 0.94 & 0.65 & 0.66 & 0.72 & 0.71 & 0.68 & 0.61 & 0.67 & 0.78 & 0.78 & 0.86 & 0.62 & 0.71 & 0.68 & 0.6 & 0.59 & 0.5 & 0.55 & 0.52 & 0.55 & 0.669 & 25 \\
\hline Japan & & 0.45 & 43 & 0.42 & 0.49 & 0.56 & 0.5 & 0.45 & 0.54 & 0.52 & 0.48 & 0.53 & 0.61 & 0.58 & 0.59 & 0.63 & 0.54 & 0.54 & 0.53 & 0.51 & 0.540 & 28 \\
\hline & & & & & 75 & & 0.75 & 74 & 0.82 & 0.83 & .74 & 0.61 & 0.93 & 0.91 & 0.69 & 0.78 & 0.51 & 0.67 & 0.67 & 55 & .743 & 23 \\
\hline & & 0.44 & & & 0.62 & 0.67 & 0.57 & 0.55 & 0.65 & 0.61 & 0.71 & 0.63 & 0.53 & 0.54 & 0.56 & 0.65 & 0.51 & 0.52 & 0.48 & 0.57 & 0.591 & 27 \\
\hline & & 0.92 & & 0.82 & 0.86 & & 0.88 & 0.88 & 0.93 & 1 & & 0.94 & 1 & 1 & 0.99 & 0.96 & 0.92 & 0.89 & 0.93 & 0.85 & 0.918 & 12 \\
\hline Poland & 0.69 & 0.74 & 0.72 & 0.59 & 0.75 & 0.85 & 0.79 & 0.86 & 0.96 & 0.99 & 0.79 & 0.52 & 0.61 & 1 & 0.97 & 1 & 0.84 & 0.9 & 0.84 & 0.82 & 0.812 & 18 \\
\hline Portugal & & 0.84 & & 0.92 & 1 & 0.84 & 0.82 & 0.75 & 0.88 & 0.93 & 0.98 & 0.83 & 1 & 0.95 & 0.94 & 0.91 & 0.82 & 0.77 & 0.73 & 0.76 & 0.873 & 13 \\
\hline & & 0.8 & & 0.81 & 0.68 & & 0.7 & 0.58 & 0.9 & 0.89 & 0.95 & 0.9 & 0.86 & 0.86 & 0.9 & 0.84 & 0.76 & 0.85 & 0.86 & 0.9 & 0.807 & 20 \\
\hline Serbia & 1 & 1 & 1 & 1 & 1 & 1 & 1 & 1 & 1 & 1 & 1 & 1 & 0.98 & 1 & 1 & 1 & 1 & 1 & 1 & 0.92 & 0.995 & 3 \\
\hline Russia & 0.85 & 0.97 & & 1 & 1 & 1 & 1 & 1 & 0.88 & 0.75 & 0.75 & 0.87 & 0.77 & 0.86 & 0.91 & 0.69 & 0.72 & 0.83 & 0.7 & 0.64 & 0.860 & 15 \\
\hline & 1 & 1 & 0.95 & 0.83 & 1 & 1 & 1 & 1 & 1 & 1 & 1 & 0.79 & 1 & 1 & 0.9 & 1 & 0.89 & 0.87 & 0.81 & 0.8 & 0.942 & 9 \\
\hline & 1 & 1 & 1 & 1 & & 1 & & 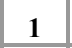 & & & & & & 1 & 1 & & 1 & 1 & 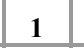 & 1 & & 1 \\
\hline & 1 & 1 & 1 & 1 & 0.89 & 1 & 0.96 & 0.86 & 0.95 & 0.93 & 0.85 & 0.8 & 0.82 & 1 & 1 & 1 & 1 & 1 & 1 & 1 & 0.953 & 8 \\
\hline USA & 1 & 0.95 & 0.85 & 0.86 & 1 & 1 & 1 & 1 & 1 & 0.97 & 1 & 1 & 1 & 1 & 1 & 1 & 1 & 1 & 1 & 1 & 0.982 & 4 \\
\hline & & & & & & & & & & & & & & & .500 & 0.260 & 0.430 & 0.41 & & & 0.220 & \\
\hline & & & & & & & & & & & & & & & & & 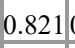 & 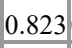 & 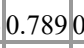 & & 0.830 & \\
\hline & 189 & 207 & Pा & 20 & 184 & 16 & 16 & 168 & 0.13 & 17 & 177 & 0.15 & 167 & 16 & 190 & 0.2 & & $.1 / 2$ & 0.2 & 0.1 & 0.17 & \\
\hline
\end{tabular}

Table 2 and Figure 2 preset comparison of call centers' efficiency per each month. The call center in Slovakia was relatively efficient during all months. Ten call centers (Romania, Nederland, South Korea, Japan, Italia, France, Denmark, Germany, Belgium and Australia) 
were inefficient in all period of 20 months. These countries have to increase the number of answered calls for $45 \%$ at least. Canada, China, Czech Republic, Serbia, and the USA were relatively efficient for a $90 \%$ of observed period

\section{Figure 2: Efficiency analysis per month}

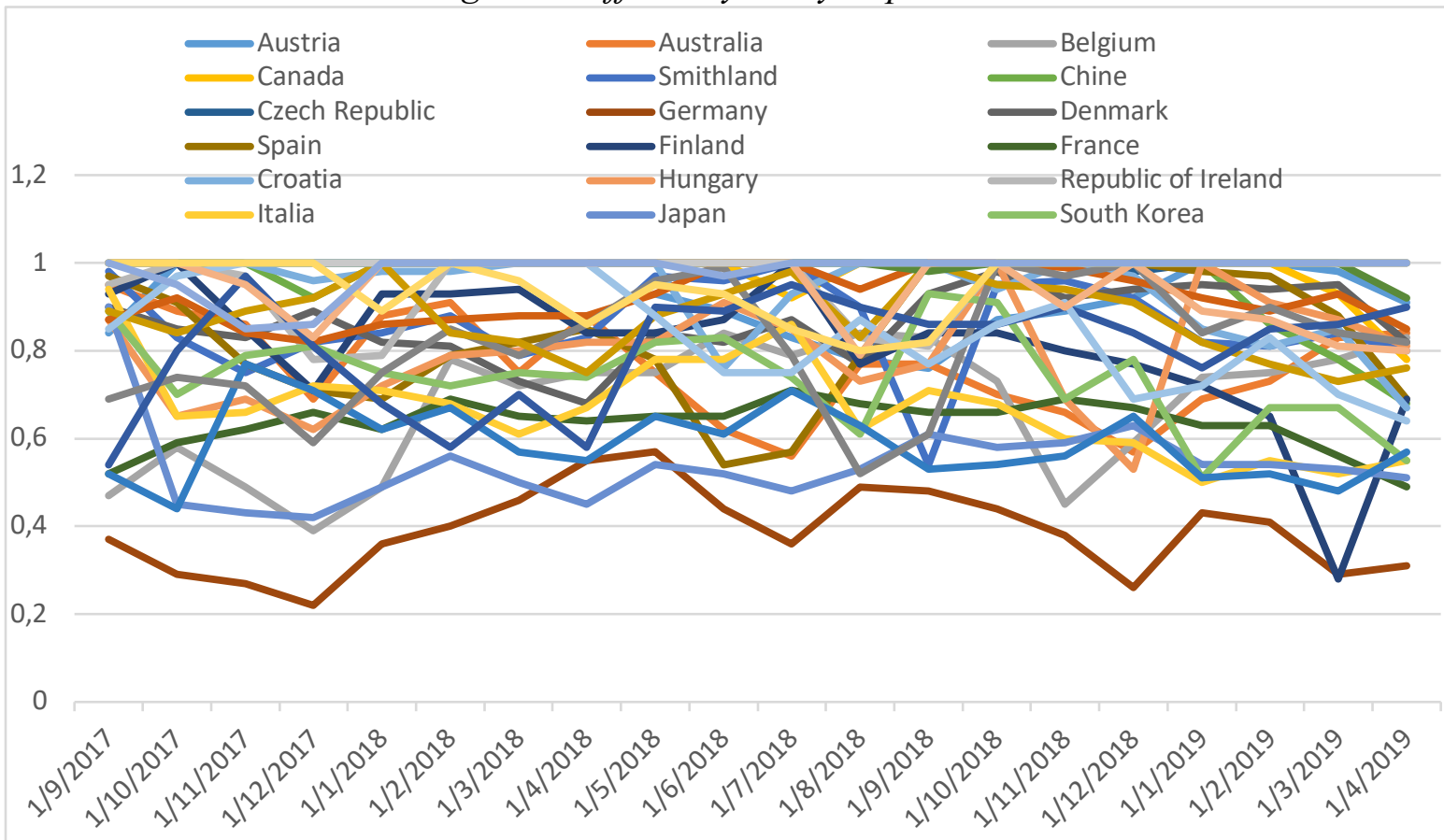

KPIs used in this study affect the efficiency dynamic. In months when call centers were an efficient, the number of answered was from $90 \%$ to $97 \%$ of offered calls which is an outstanding result. During those months, co-workers were organized in a right way since $97 \%$ of received calls were timely answered within a 60 seconds. Therefore, it can be concluded that the relative efficient call centre made a good task assignments and a well-planned schedule to cover peak hours in a better way than the inefficient ones.

Call centers with an efficiency rate above 0.9 are generally small call centers in small countries. On the other hand, call centers in Canada, China and USA are efficient despite a large number of potential customers. This is due to so in such centres, it is easy to planning, monitoring, and evaluation of the activities even in real-time. Call centers in Germany and Japan (with the lowest efficiency rates) have a large number of employees, and it is complicated to follow each agent. Still, it is mostly done on an annual basis when agents check their goals and new tasks.

\section{CONCLUSION}

Different call centers use different indicators to measure their performance, but each center has key responsibilities and KPIs used in its management. Therefore, call center KPIs analysis is imperative when assessing efficiency and effectiveness. The same goal is to put the customer first and if the call center works with limited technologies, teams, knowledge, then the overall performance and KPIs will be below the planned ones. Given that the world of customer needs and experiences is a quick target based on expectations, contact centers must anticipate future needs and make an appropriate forecast based on that. Only in this way, the contact centers will be ready for a competitive environment which will expand and 
change in the future. In this study, we examined the efficiency of 29 customers supports call centers in different countries but within one multinational company. Assuming the same operating policy and same KPIs, we used DEA model under the constant to return to scale. Standard KPIs are selected to be the input and output parameters of the analysis. Namely, we used number of employees, average handling time and the number of offered calls as inputs and number of answered calls and service level as outputs. The results indicated that smaller countries such as Slovakia and the Chez Republic are more efficient on average since they could have enough time and other resources to answer the requests effectively. Their organizations and work plan could be a good benchmark for inefficient call centers in similar countries such as Netherland. On the other hand, there are efficient call centers in large countries such as Canada, China and USA. Their organization could be a good example for Germany or Japan. But, benchmark-setting should be done very carefully taking into account some intangible factors, such as culture and habits, besides efficiency.

Further research can be directed towards intangibles like knowledge and accuracy, responsiveness, assurance, and empathy, then procedures for employees' improving through the training, improving the assessment of service, taking into account other relevant criteria such as quality of the service provider, etc. The case study can also be directed to other fields, including measuring the satisfaction of service users, where the proposed methodology would represent the general paradigm for measuring efficiency according to all the relevant criteria.

\section{REFERENCES}

Anderson, G., Mark R., \& Selby D.(2007). "Evaluating a performance of a customer support resource in the context of a peer group". U.S. Patent Application, 11/338,413.

Aksin, Z., Armony, M., \&Mehrotra, V. (2007). "The modern call center: A multi-disciplinary perspective on operations management research". Production and operations management, 16(6), 665-688.

Banker, R.D., \& Podinovski, V.V. (2017). "Novel theory and methodology developments in data envelopment analysis". Annals of Operations Research, Vol. 250, No. 1, pp. 1-3.

Carlaw, M., Carlaw, P., Deming, V. K., \&Friedmann, K. (2003). "Managing and motivating contact center employees", Tools and techniques for inspiring outstanding performance from your frontline stafi New York: McGraw-Hill.

Charnes, A., Cooper, W.W., \& Rhodes, E. (1978), "Measuring the efficiency of decisionmaking units", European Journal of Operational Research, Vol. 2, pp. 429-44.

Charnes, A., Cooper, W.W., \& Rhodes, E. (1981), "Evaluating program and managerial efficiency: An application of data envelopment analysis to program follow through", Management Science, Vol. 27, pp. 668-697.

Chicu, D., Ryan, G., \&Mirela, V. (2016). "Determinants of customer satisfaction in call centres". European Accounting and Management Review, 2(2), 20-41.

Delaney, P. J. (2005). U.S. Patent No. 6,937,715. Washington, DC: U.S. Patent and Trademark Office.

Dučić, A. (2018), "Efficiency measurement of co-workers in contact center ", Undergraduate thesis, University of Belgrade, Faculty of Oranizational Science, September 2018.

Khodamoradi, M., Behzadi, M. H., \&Rostamy-MaleKhalifeh, M. (2016). "Evaluating of staff's performance with job satisfaction and Organisational Commitment approach by DEA (case study: Khuzestan Oxin Steel Company)". International Journal of Data Envelopment Analysis, 4(2), 945-949.

Malhotra, N., \& Mukherjee, A. (2004). "The relative influence of organisational commitment and job satisfaction on service quality of customer-contact employees in banking call centres". Journal of Services Marketing, 18, 162- 174. 
Moazeni, S., \& Andrade, R. (2018, July). "A Data-Driven Approach to Predict an Individual Customer's Call Arrival in Multichannel Customer Support Centers". In 2018 IEEE International Congress on Big Data (BigData Congress) (pp. 66-73). IEEE.

Mohammadi, S., Tarokh, M. J., \&Mohammdi, E. (2017). "Robust Optimisation and Confidence Interval DEA for Efficiency Evaluation with Intervals Case Study: Evaluating CRM Units in a Call Center in Tehran". International Journal of Data Envelopment Analysis, 5(1), 1155-1166.

Popović, M., Savić, G., Kuzmanović, M., \& Martić, M. (2020). "Using Data Envelopment Analysis and Multi-Criteria Decision-Making Methods to Evaluate Teacher Performance in Higher Education". Symmetry, 12(4), 563.

PoykayilJayanandaPanicker, A. (2002). "Evaluation of the Performance of Customer Service Representatives in a Call Center Using DEA/Network Model/Fuzzy Sets", Doctoral dissertation, Virginia Tech.

Radovanović, S., Radojičić, M., \&Savić, G. (2014). "Two-phased DEA-MLA approach for predicting efficiency of NBA players". Yugoslav Journal of Operations Research, 24(3), 347358.

Ruiz, J. L., Pastor, D., \& Pastor, J. T. (2013). "Assessing professional tennis players using data envelopment analysis (DEA) ". Journal of Sports Economics, 14(3), 276-302.

Sherman, H. D., \& Zhu, J. (2006). "Service productivity management: Improving service performance using data envelopment analysis (DEA) ". Springer Science \& Business Media.

So, S. (2007). "An Empirical Analysis on the Operational Efficiency of CRM call centers in Korea ". International Journal of Computer Science and Network Security, 7(12), 171-178.

Tongzon, J. (2001). "Efficiency measurement of selected Australian and other international ports using data envelopment analysis", Transportation Research Part A: Policy and Practice, Vol. 35, No.2, pp. 107-122.

Tsai, C. F., \& Lu, Y. H. (2009). "Customer churn prediction by hybrid neural networks". Expert Systems with Applications, 36(10), 12547-12553.

Zbranek, P. (2013). "Data envelopment analysis as a tool for evaluation of employees' performance". ActaOeconomicaetInformatica, 16(394-2016-24293), 12-21. 